\title{
Radiologic Burden of New Tumor
}

National Cancer Institute

\section{Source}

National Cancer Institute. Radiologic Burden of New Tumor. NCI Thesaurus. Code C158776.

The estimate of the number of cells, or size of the tumor from the results of an imaging modality. 